\title{
Nintedanib-A Potential New Therapy for Systemic Sclerosis-associated Interstitial Lung Disease
}

\author{
Tejaswini Kulkarni, ${ }^{1}$ Audrey Haywood, ${ }^{2}$ and Anoop M Nambiar ${ }^{2,3}$ \\ 1. Department of Medicine, Division of Pulmonary and Critical Care Medicine, University of Alabama at Birmingham, Birmingham AL, USA, \\ 2. Department of Medicine, Division of Pulmonary and Critical Care Medicine, University of Texas Health Science Center at San Antonio, TX, USA; \\ 3. South Texas Veterans Health Care System, San Antonio, TX, USA
}

DOI: https://doi.org/10.17925/USPRD.2020.5.1.28

S ystemic sclerosis (SSc) is an autoimmune disorder characterized by inflammation and fibrosis of the skin and other internal organs, especially the lungs. SSC-associated interstitial lung disease (SSC-ILD) is the most common complication of SSC and leading cause of morbidity and mortality in these patients. As such, there is a significant unmet need for earlier, more accurate diagnosis and implementation of safe, more effective therapies. The pathogenesis of SSc-ILD is a complex process that involves cellular and humoral immune dysregulation, inflammatory mediators, and vascular and fibrotic mechanisms. Traditional therapeutic strategies have focused on reducing chronic inflammation and the immunomodulation. Mycophenolate mofetil is currently considered the first-line therapy for SSC-ILD based on the Scleroderma Lung Study (SLS-II), which showed equivalent efficacy with fewer adverse events compared with cyclophosphamide. Nintedanib is an intracellular tyrosine kinase inhibitor with antifibrotic, anti-inflammatory, and vascular remodeling effects. Currently approved for idiopathic pulmonary fibrosis, nintedanib was recently evaluated for safety and efficacy in SSC-ILD. Based upon the results of this pivotal trial, nintedanib is the first ever treatment approved by the US Food and Drug Administration for SSC-ILD. This review focuses on the pathogenesis of SSC-ILD and the role of nintedanib in the treatment algorithm for these patients.

\section{Keywords}

Systemic sclerosis, scleroderma, interstitial lung disease, nintedanib

Disclosures: Tejaswini Kulkarni, Audrey Haywood, and Anoop M Nambiar have no financial or non-financia relationships or activities to declare in relation to this article.

Review Process: Double-blind peer review.

Compliance with Ethics: This article involves a review of the literature and did not involve any studies with human or animal subjects performed by any of the authors.

Authorship: The named authors meet the Internationa Committee of Medical Journal Editors (ICMJE) criteria for authorship of this manuscript, take responsibility for the integrity of the work as a whole, and have given final approval for the version to be published.

Access: This article is freely accessible at touchRESPIRATORY.com (c) Touch Medical Media 2020.

Received: January 7, 2020

Accepted: February 25, 2020

Published Online: April 9, 2020

Citation: US Respiratory and Pulmonary Diseases. 2020;5(1):28-32

Corresponding Author: Anoop M Nambiar,

University of Texas Health San Antonio, 7703 Floyd Curl

Drive, MC 7885, San Antonio, TX 78229, USA.

E:nambiar@uthscsa.edu

Support: No funding was received for

the publication of this article.
Systemic sclerosis (SSC) is an autoimmune disorder characterized by inflammation and fibrosis of the skin and other organs. It has a range of clinical manifestations, and the typical internal organs involved include the lungs, kidneys, heart, and gastrointestinal tract. Though it is an uncommon condition, the mortality rate of this disease is higher than any other rheumatologic condition, ${ }^{1}$ and the majority of deaths occurring in SSc are related to pulmonary manifestations, including interstitial lung disease (ILD) and pulmonary arterial hypertension. ${ }^{2}$ SSC is subdivided into two subtypes, limited cutaneous SSC (ICSSc) and diffuse cutaneous SSc (dcSSc), based on the extent of skin involvement, with limited disease indicating that the dermatologic sclerosis is confined to the hands, distal extremities, face, and neck; while diffuse disease is characterized by more extensive sclerosis, especially of the internal organs such as the lungs.

With a prevalence of up to $90 \%$ of patients, ILD may complicate SSC as a result of lung inflammation and/or progressive fibrosis. ILD may occur with either SSc subtype, although more frequently with dSSC. ${ }^{3}$ Given the significant morbidity and mortality of SSC-associated ILD (SSC-ILD), recent studies have been performed in an attempt to identify novel treatment strategies to slow or reverse the progression of the disease. Nintedanib, a small molecule tyrosine kinase inhibitor, currently approved for the treatment of idiopathic pulmonary fibrosis (IPF) was recently shown to similarly reduce the rate of annual lung function decline in patients with SSC-ILD. ${ }^{4}$ Here, we discuss the pathogenesis of SSC-ILD and its common clinical manifestations. The objective of this article is to review the current therapies for SSC-ILD and discuss the role of nintedanib in the treatment of these patients.

\section{Pathogenesis of systemic sclerosis-associated interstitial lung disease}

The pathogenesis of SSC-ILD is a complex process that involves cellular and humoral immune dysregulation, inflammatory mediators, and fibrotic mechanisms. ${ }^{5}$ Patients who develop SSc could have underlying genetic predisposition to the disease with an environmental trigger that actually initiates the disease process. ${ }^{6}$ Similar to IPF, the initial injury begins in the alveolar epithelium and endothelium, followed by a cascade of both innate and adaptive immunological responses. Proinflammatory cytokines such interleukin-8 and tumor necrosis factor- $\alpha$ are released during the 
inflammatory phase. Activated macrophages, among other cells, also release profibrotic factors such as transforming growth factor- $\beta$, connective tissue growth factor, and platelet derived growth factor (PDGF). Differentiation and proliferation of myofibroblasts under the influence of these profibrotic factors, key effector cells well-known in the pathogenesis of IPF, have more recently been shown play a crucial role in the extracellular matrix (ECM) remodeling and disease progression in SSC-ILD. ${ }^{9}$ Fundamental to fibrotic ILDS, myofibroblast activation and excessive ECM deposition results in a perpetual self-sustaining cycle of fibrosis.

Vascular involvement is another key driver of SSC and likely contributes to the majority of organ involvement that occurs. Endothelin-1 has known vasoconstrictive properties but has also been shown to have mitogenic effects and enhancement of collagen synthesis. ${ }^{10}$ It is thought to be important in both the vascular and fibrotic changes that occur in SSc. ${ }^{11}$ Endothelin-1 has been noted to occur in higher concentrations in patients with SSC when compared with healthy control subjects and was inversely correlated with diffusion capacity. ${ }^{12}$ Endothelial cell apoptosis may contribute further to perpetuation of tissue injury/repair processes, but its role is incompletely understood. While this process has greater involvement in development of pulmonary hypertension, it is thought to be important in both the vascular and fibrotic changes that occur in SSC. ${ }^{11}$

\section{Clinical considerations}

ILD is the most common pulmonary manifestation of SSC. The reported prevalence of ILD in patients with SSC may be up to $90 \%,{ }^{3}$ but varies depending on the distribution of serological pattern, definition of ILD, and the population studied (e.g. IcSSc, dcSSc, or a combination). While restrictive lung disease does occur in both dcSSC and IcSSC, it appears to occur with higher frequency in dcSSc.13 The incidence of ILD is highest among the subgroup of patients with anti-topoisomerase I antibody (anti-Scl-70) positivity and dcSSc. ${ }^{14}$ Presence of anti-Scl-70 antibodies has been associated with lower and more rapid decline in forced vital capacity (FVC), while presence of anti-centromere antibodies has been associated with less restriction, isolated diffusion defects, and pulmonary hypertension. ${ }^{13,15}$ Radiographic findings of ILD have also been shown to be less frequent in the presence of anti-centromere antibodies. ${ }^{13}$ Additional patient characteristics such as gender and race may potentially contribute to the development of ILD among patients with SSC. 16,17 $^{1,17}$

Presenting symptoms generally include dyspnea, fatigue, reduced exercise capacity, and cough. Exam findings, including fine, bibasilar, and inspiratory crackles, may suggest underlying ILD, and should prompt further evaluation with pulmonary function tests (PFTS), high-resolution computed tomography (HRCT) chest scans, and/or echocardiogram. PFT abnormalities including restriction and diffusion capacity deficits have been demonstrated in $>70 \%$ of patients, although several patients may have normal lung function in the presence of early ILD. Radiographic findings consistent with fibrosis were seen in at least one-third of patients with scleroderma, ${ }^{18}$ while some other studies have reported prevalence up to $90 \%{ }^{3}$ Nevertheless, given the progressive nature of pulmonary fibrosis, early evaluation with HRCT is warranted, particularly among patients with risk factors. The most common pattern of fibrosis on HRCT in SSC-ILD is nonspecific interstitial pneumonia (NSIP) with ground-glass opacities and subpleural sparing. ${ }^{19}$ Usual interstitial pneumonia pattern, characterized by basal predominant peripheral reticulations, traction bronchiectasis, and honeycomb changes, is present in one-third of these patients and portends a poorer prognosis. ${ }^{20,21}$ The NSIP histology tends to be the fibrotic form more often than cellular NSIP, but the prognosis has not been shown to differ between the types of NSIP. ${ }^{21}$ Among patients with a histopathologic pattern of usual interstitial pneumonia, SSc is associated with increased presence of lymphocytic infiltrates compared to those with IPF.

\section{Current therapies}

Therapies for ILD related to SSc have traditionally focused on reducing the chronic inflammation that is believed to lead to fibrosis. These often include corticosteroids and other immunosuppressive agents. Despite these therapies, 3-year survival in patients with serious cardiac or pulmonary involvement is only about $50 \% .{ }^{22}$ Physiologic parameters, including FVC, appear to be the best method of monitoring progression of fibrotic ILD, and most studies use FVC as the primary endpoint in evaluation of potential therapies for SSC-ILD. ${ }^{23}$ Key positive randomized control trials in SSC-ILD are outlined in Table 1

Mycophenolate mofetil (MMF) is currently considered the first-line therapy for SSC-ILD based on the Scleroderma Lung Study (SLS)-II. This study was a multicenter, randomized, double-blind, parallel-group trial in 126 patients with SSC-ILD that compared the efficacy and safety of MMF (target dose of 1,500 mg twice daily) for 24 months versus oral cyclophosphamide (target dose $2 \mathrm{mg} / \mathrm{kg}$ per day) for 12 months followed by placebo for 12 months. Although there was no significant difference in the primary endpoint of change in FVC (percent predicted) at 2 years between groups, both groups demonstrating a significant increase in FVC, fewer patients stopped MMF prematurely and there were fewer treatment-related serious adverse events in patients on MMF compared with cyclophosphamide. ${ }^{24}$ Based on the SLS-I and II trials, cyclophosphamide is considered as an alternative therapeutic option.25,24 In SLS-I, cyclophosphamide showed modest improvements in lung volume, dyspnea score, quality of life, and HRCT score compared to placebo when studied over 12 months. ${ }^{25,26}$ However, treatment with cyclophosphamide may be complicated by significant serious adverse events, including hemorrhagic cystitis, neutropenia, opportunistic infections, and bladder cancer; thus, making it a less appealing first-line agent.

There are very limited data to support the efficacy of corticosteroids in SSC-ILD, 27,28 but rather evidence of risk of scleroderma renal crisis, particularly with higher doses. ${ }^{29,30}$ While a majority of patients receive corticosteroids at some point in their disease course, only a few small studies have shown marginal benefit of corticosteroid use over no immunosuppression. ${ }^{31,32}$ In a subgroup of patients with significant inflammation and ground-glass opacities on HRCT at presentation, corticosteroids might be utilized in conjunction with MMF titration. The generally accepted clinical approach focuses on cautious utilization of corticosteroids during acute exacerbations but is not recommended as a monotherapy in patients with SSC-ILD.

Azathioprine has been considered in combination therapy with cyclophosphamide, ${ }^{33}$ but the evidence to use it as monotherapy is less compelling. Finally, rituximab, a monoclonal antibody that targets CD20-positive B-lymphocytes, has been employed among patients with refractory or progressive ILD but the paucity of randomized controlled trials evaluating the efficacy of rituximab in SSC-ILD limits its utility. While these traditional immunosuppressive therapies have focused primarily on chronic inflammation in SSC-ILD, the advent of antifibrotic therapies approved for IPF have helped usher in a paradigm shift in the management of SSC-ILD. 
Table 1: Key randomized controlled trials for systemic sclerosis-associated interstitial lung disease

\begin{tabular}{|c|c|c|c|c|c|}
\hline Study & Study design & Intervention & $\mathrm{N}$ & Primary outcome & Other key findings \\
\hline $\begin{array}{l}\text { Scleroderma } \\
\text { Lung Study-125 }\end{array}$ & $\begin{array}{l}\text { Year 1: Randomized, } \\
\text { double blind, } \\
\text { placebo-controlled trial } \\
\text { Year 2: Follow-up } \\
\text { without drug }\end{array}$ & $\begin{array}{l}\mathrm{CYC} \leq 2 \mathrm{mg} / \mathrm{kg} / \mathrm{day} ; \\
\text { placebo }\end{array}$ & 158 & $\begin{array}{l}\text { Mean absolute difference in } \\
\text { adjusted } 12 \text {-month \% FVC: } \\
2.53 \%(95 \% \mathrm{Cl} 0.28-4.79) \text {, } \\
\text { favoring } \mathrm{CYC}(\mathrm{p}<0.03)\end{array}$ & $\begin{array}{l}\text { - Difference in \% FVC maintained at } 24 \text { months } \\
\text { - Treatment-related benefit in quality of life outcomes, } \\
\text { skin thickening } \\
\text { - More adverse events in CYC group }\end{array}$ \\
\hline $\begin{array}{l}\text { Scleroderma } \\
\text { Lung Study- } \|^{24}\end{array}$ & $\begin{array}{l}\text { 2-year randomized, } \\
\text { double-blind, two-arm } \\
\text { active medication/ } \\
\text { placebo-controlled trial }\end{array}$ & $\begin{array}{l}\text { Arm 1: MMF 1,500 mg } \\
\text { twice a day ( } 24 \text { months) } \\
\text { Arm 2: Cytoxan } \\
\leq 2 \mathrm{mg} / \mathrm{kg} / \text { day } \\
\text { (12 months) then } \\
\text { placebo (12 months) }\end{array}$ & 126 & $\begin{array}{l}\text { \% FVC improved by } 2.19 \% \\
(95 \% \mathrm{Cl} 0.53-3.84) \text { in the } \\
\text { MMF arm and } 2.88 \%(95 \% \mathrm{Cl} \\
1.19-4.58) \text { in the CYC arm } \\
(\mathrm{p}=0.24)\end{array}$ & $\begin{array}{l}\text { - Leucopenia and thrombocytopenia were more } \\
\text { frequent with CYC than MMF } \\
\text { - Greater number of patients prematurely withdrew or } \\
\text { failed treatment in CYC arm than MMF } \\
\text { - Within treatment improvements in \% FVC, skin score } \\
\text { and whole-lung HRCT scores at } 24 \text { months in both } \\
\text { arms in post-hoc analysis }\end{array}$ \\
\hline $\begin{array}{l}\text { Safety and } \\
\text { Efficacy of } \\
\text { Nintedanib } \\
\text { in Systemic } \\
\text { Sclerosis }^{4}\end{array}$ & $\begin{array}{l}\text { 52-week randomized, } \\
\text { double-blind, } \\
\text { placebo-controlled trial }\end{array}$ & $\begin{array}{l}\text { Nintedanib } 150 \text { mg } \\
\text { twice a day }\end{array}$ & 576 & $\begin{array}{l}\text { Adjusted annual rate of } \\
\text { change in FVC: }-52.4 \mathrm{~mL} \text { per } \\
\text { year in Nintedanib group } \\
\text { and }-93.3 \mathrm{~mL} \text { per year in the } \\
\text { placebo group (difference } \\
41 \mathrm{~mL} / \text { year, } 95 \% \mathrm{Cl} \text { 2.9-79; } \\
\mathrm{p}=0.04 \text { ) }\end{array}$ & $\begin{array}{l}\text { - No difference in modified Rodnan skin score at } \\
\text { week } 52 \\
\text { - Diarrhea reported in } 75.7 \% \text { in nintedanib group versus } \\
31.6 \% \text { in placebo group }\end{array}$ \\
\hline
\end{tabular}

$\mathrm{Cl}=$ confidence interval $; \mathrm{CYC}=$ cyclophosphamide; $F V C=$ forced vital capacity $; \mathrm{MMF}=$ mycophenolate mofetil.

\section{Nintedanib and its mechanism of action}

Nintedanib, an intracellular tyrosine kinase inhibitor, was shown to reduce the rate of FVC decline in patients with IPF in the INPULSIS trials (ClinicalTrials.gov identifier: NCT01619085) (34 $^{34}$ and was approved for treatment of IPF at a dose of $150 \mathrm{mg}$ twice daily. Several in vitro studies show that nintedanib has antifibrotic, anti-inflammatory, and vascular remodeling effects with resultant attenuation of progression of fibrosis in preclinical models of IPF. ${ }^{35}$ Given the considerable similarities in the pathogenesis of IPF and SSC-ILD, particularly myofibroblast differentiation and dysregulated ECM deposition, it has been hypothesized that a similar effect of nintedanib may be seen in SSC-ILD and has been reported in in vitro studies of SSC-ILD and SSC skin fibrosis. Nintedanib was shown to inhibit the differentiation and migration of lung fibroblasts derived from patients with SSC-ILD; it also blocked PDGF-induced differentiation of normal lung fibroblasts to myofibroblasts, with resultant reduction in ECM expression. ${ }^{36}$

Nintedanib has also been shown to have similar effects on dermal fibroblasts obtained from patients with SSc compared to healthy subjects. ${ }^{37}$ In this study, nintedanib also prevented bleomycin-induced skin fibrosis and ameliorated fibrosis in a chronic graft-versus-host disease model and in tight-skin-1 mice. Reduction in pulmonary and dermal fibrosis demonstrated by decreased myofibroblast counts and ECM deposition has also been reported in nintedanib treated fibrosis fos-related antigen 2 (Fra2)-transgenic mice. ${ }^{38}$ Additionally, a significant effect on pulmonary vascular remodeling via inhibition of the proliferation of pulmonary vascular smooth muscle cells in these Fra2-transgenic mice, was demonstrated with nintedanib. ${ }^{38}$

\section{Nintedanib-evidence from clinical trials}

Based on the rationale that nintedanib can modulate the fundamental process of myofibroblast differentiation and ECM deposition in all ILDS, The Safety and Efficacy of Nintedanib in Systemic Sclerosis (SENSCIS) trial (ClinicalTrials.gov identifier: NCT02597933) recently evaluated use of nintedanib in patients with SSC-ILD. This was a multinational, randomized, double-blind, placebo-controlled, parallel-group trial that included 576 adult patients diagnosed with SSC with HRCT chest scan showing fibrosis affecting at least $10 \%$ of the lungs, FVC of at least $40 \%$ predicted value, and the diffusing capacity of the lungs for carbon monoxide (DLCO) of 30-89\% predicted value. Four of the 819 patients screened had clinically significant pulmonary hypertension defined by either clinical or echocardiographic evidence of right heart failure, cardiac index $\leq 2 \mathrm{~L} /$ minute per square of body surface area, or history of parenteral therapy with vasodilators, and were excluded from the study. Patients were randomized to either nintedanib $150 \mathrm{mg}$ twice daily or placebo with primary efficacy evaluation conducted at week 52. The primary endpoint was the annual rate of decline in FVC.

The trial investigators found the annual rate of change in FVC over 52 weeks to be lower in the nintedanib group $(-52.4 \pm 13.8 \mathrm{~mL})$ compared with the placebo group $(-93.3 \pm 13.5 \mathrm{~mL})$ with benefit becoming evident by week 12 . Importantly, the benefit of nintedanib over placebo was present but less pronounced in patients taking mycophenolate at baseline compared with those not on mycophenolate. There was no improvement in health-related quality of life nor evidence that nintedanib modifies the course of other organs affected by SSc. Sixteen percent of patients in the nintedanib group experienced an adverse event that led to discontinuation compared with $8.7 \%$ of patients in the placebo group. Diarrhea was the most common adverse event, occurring in almost $76 \%$ of patients taking the drug, and was mild to moderate in most patients. About $5 \%$ of patients receiving nintedanib had elevations in aminotransferases reaching three times the upper limit of normal. ${ }^{4}$ On September 6, 2019, nintedanib was approved by the US Food and Drug Administration (FDA) as the first and only treatment for SSC-ILD. ${ }^{39}$

In addition, nintedanib was evaluated in patients with progressive fibrosing $I L D$, including SSC-ILD, in the INBUILD trial. ${ }^{40}$ This was a randomized, double-blind, placebo-controlled trial that included a total of 663 patients, 
of which 39 (5.9\%) had SSc-ILD. Key inclusion criteria were fibrosing lung disease with $>10 \%$ of lung volume affected based on HRCT, confirmed disease progression despite use of conventional therapies within 24 months prior to enrollment, FVC of at least 45\% predicted, and DLCO of $30-79 \%$ predicted. Patients were randomized to receive either nintedanib $150 \mathrm{mg}$ twice daily or placebo. The primary endpoint was annual rate of FVC decline followed over 52 weeks. The results demonstrated a statistically significant reduction in the FVC rate of decline: $-80.8 \mathrm{~mL}$ per year in the nintedanib group and $-187.8 \mathrm{ml}$ per year with placebo. The difference was more pronounced in patients with a usual interstitial pneumonia-like pattern of fibrosis. Diarrhea was the most common adverse event in the nintedanib group, and more people required dose reductions or discontinuation of nintedanib when compared with placebo. ${ }^{40}$

\section{Treatment decision making}

The decision to initiate treatment in patients with SSC-ILD can be a challenging one that requires integration of several patient-related and disease-specific features. Although patients with SSC-ILD may have increased mortality rates, the currently available treatments have potentially significant toxicity with only modest efficacy. Survival prediction tools, such as those by Goh et al., ${ }^{41}$ and the SADL model by Morisset et al., ${ }^{42}$ may be helpful in predicting short-term mortality and aid in treatment decisions. With the advent of antifibrotic therapy, a nuanced understanding of the risks and benefits of all therapeutic options in a disease previously treated with only immunosuppression is crucial. There is increasing evidence emphasizing the importance of early treatment for ILD; larger centers are now focusing on annual screening of patients with SSC with PFTs and/or HRCTS. However, guidelines for recommendation of treatment algorithms are yet to be published.

Given the potential benefit from initial immunosuppressive therapy during the inflammatory phase in SSC-ILD, MMF remains the first line of therapy given its efficacy in modulating both pulmonary and extra-pulmonary manifestations of SSC. ${ }^{43,24}$ MMF therapy has been shown to improve lung function as measured by FVC while nintedanib only slowed down disease progression in the SENSCIS trial. Further, there was only a modest additional benefit of nintedanib to MMF therapy among patients with stable disease; the annual rate of change in FVC among patients on background MMF was $-40.2 \mathrm{~mL}$ per year in the nintedanib arm compared with $-66.5 \mathrm{~mL}$ per year in the placebo arm. ${ }^{4}$ In the absence of randomized controlled trials evaluating MMF or cyclophosphamide versus nintedanib, we believe that nintedanib should only be utilized among patients with SSC-ILD who decline, or are intolerant to, MMF and/or cyclophosphamide therapy or demonstrate disease progression despite these initial therapies. The benefit of treatment with nintedanib over placebo ( \pm background MMF) was noticeable only beyond the 12-week mark ${ }^{4}$ and should be a consideration in the treatment algorithm. As mentioned earlier, patients with clinically significant pulmonary hypertension were excluded from the SENSCIS trial; therefore, the potential benefits of nintedanib in these patients is unknown. The majority of these patients require long-term maintenance therapy to preserve their lung function and should be monitored with PFTs every 3-6 months. Overall, nintedanib was tolerated at least as well as in IPF despite known gastrointestinal issues that are common among patients with SSc. The extension trial, SENSCIS-ON, will assess the long-term safety of nintedanib in SSC-ILD and may shed more light on its utility in clinical practice.

\section{Conclusions}

SSC-ILD is a chronic, progressive fibrotic lung disease associated with increased mortality. Clinical practice guidelines to best inform a therapeutic approach for these patients is absent; MMF is currently considered the standard of care based on the SLS-II. However, recent studies evaluating nintedanib in SSC-ILD have been encouraging and led to FDA approval of nintedanib as the first and only for SSC-ILD. Many key questions, such as when to initiate antifibrotic therapy, how best to measure the treatment response, and how long treatment should be continued, remain unanswered.
1. Denton CP, Khanna D. Systemic sclerosis. Lancet (London, England). 2017;390:1685-99.

2. Tyndall AJ, Bannert B, Vonk M, et al. Causes and risk factors for death in systemic sclerosis: a study from the EULAR Scleroderma Trials and Research (EUSTAR) database. Ann Rheum Dis. 2010;69:1809-15.

3. White B. Interstitial lung disease in scleroderma. Rheum Dis Clin North Am. 2003;29:371-90

4. Distler $\mathrm{O}$, Highland KB, Gahlemann M, et al. Nintedanib for systemic sclerosis-associated interstitial lung disease. N Engl J Med. 2019;380:2518-28.

5. Wollin L, Distler JH, Denton CP, Gahlemann M. Rationale for the evaluation of nintedanib as a treatment for systemic sclerosisassociated interstitial lung disease. I Scleroderma Relat Disord. 2019;4:212-8.

6. Pattanaik D, Brown M, Postlethwaite BC, Postlethwaite AE. Pathogenesis of systemic sclerosis. Front Immunol. 2015;6:272.

7. Akter T, Silver RM, Bogatkevich GS. Recent advances in understanding the pathogenesis of scleroderma-interstitial lung disease. Curr Rheumatol Rep. 2014:16:411.

8. Kulkarni T, O'Reilly P, Antony VB, et al. Matrix remodeling in pulmonary fibrosis and emphysema. Am J Respir Cell Mol Biol. 2016;54:751-60.

9. Valenzi E, Bulik M, Tabib T, et al. Single-cell analysis reveals fibroblast heterogeneity and myofibroblasts in systemic sclerosis-associated interstitial lung disease. Ann Rheum Dis. 2019;78:1379-87.

10. Kahaleh MB. Endothelin, an endothelial-dependent vasoconstrictor in scleroderma. Enhanced production and profibrotic action. Arthritis Rheum. 1991;34:978-83.

11. Vancheeswaran $R$, Magoulas $T$, Efrat $G$, et al. Circulating endothelin-1 levels in systemic sclerosis subsets - a marker of fibrosis or vascular dysfunction? J Rheumatol. 1994;21:1838-44.

12. Hajialilo M, Noorabadi P, Tahsini Tekantapeh S, Malek Mahdavi A Endothelin-1, $\alpha$-Klotho, 25(OH) Vit D levels and severity of disease in scleroderma patients. Rheumatol Int. 2017;37:1651-7.

13. Kane GC, Varga J, Conant EF, et al. Lung involvement in systemic sclerosis (scleroderma): relation to classification based on extent of skin involvement or autoantibody status. Respir Med. 1996;90:223-30

14. Walker UA, Tyndall A, Cziriák L, et al. Clinical risk assessment of organ manifestations in systemic sclerosis: A report from the EULAR Scleroderma Trials and Research group database. Ann Rheum Dis. 2007:66:754-63

15. Assassi S, Sharif R, Lasky RE, et al. Predictors of interstitial lung disease in early systemic sclerosis: a prospective longitudinal study of the GENISOS cohort. Arthritis Res Ther. 2010;12:R166.

16. Lo Monaco A, Bruschi M, La Corte R, et al. Epidemiology of systemic sclerosis in a district of northern Italy. Clin Exp Rheumatol. 2011;29(2 Suppl. 65):S10-4.

17. Al-Sheikh $\mathrm{H}$, Ahmad Z, Johnson SR. Ethnic variations in systemic sclerosis disease manifestations, internal organ involvement, and mortality. J Rheumatol. 2019;46:1103-8.

18. Owens $G R$, Fino $G J$, Herbert $D L$, et al. pulmonary function in progressive systemic sclerosis. Chest. 1983;84:546-50.

19. Desai SR, Veeraraghavan $S$, Hansell DM, et al. CT features of lung disease in patients with systemic scerosis: Comparison with idiopathic pulmonary fibrosis and nonspecific interstitial pneumonia. Radiology. 2004:232:560-7.

20. Fischer A, Swigris JJ, Groshong SD, et al. Clinically significant interstitial lung disease in limited scleroderma. Chest. 2008;134:601-5.

21. Bouros D, Wells AU, Nicholson AG, et al. Histopathologic subsets of fibrosing alveolitis in patients with systemic sclerosis and their relationship to outcome. Am J Respir Crit Care Med. 2002;165:1581-6.

22. Sierra-Sepúlveda A, Esquinca-González A, Benavides-Suárez SA, et al. Systemic Sclerosis pathogenesis and emerging therapies, beyond the fibroblast. Biomed Res Int. 2019;2019:1-15.

23. Jegal Y, Kim DS, Shim TS, et al. Physiology is a stronger predictor of survival than pathology in fibrotic interstitial pneumonia. Am J Respir Crit Care Med. 2005;171:639-44.

24. Tashkin DP, Roth MD, Clements PJ, et al. Mycophenolate mofetil versus oral cyclophosphamide in scleroderma-related interstitia lung disease (SLS II): a randomised controlled, double-blind, parallel group trial. Lancet Respir Med. 2016;4:708-19.

25. Tashkin DP, Elashoff R, Clements PJ, et al. Cyclophosphamide versus placebo in scleroderma lung disease. N Eng/ I Med. 2006;354:2655-66.

26. Goldin J, Elashoff R, Kim HJ, et al. Treatment of sclerodermainterstitial lung disease with cyclophosphamide is associated with less progressive fibrosis on serial thoracic high-resolution CT scan than placebo. Chest. 2009;136:1333-40.

27. Iudici M, Valentini G, Van der Goes MC, Bijlsma JWJ. Glucocorticoids in systemic sclerosis: Weighing up the benefits and risks - a systematic review. Clin Exp Rheumatol. 2013:31(2 Suppl. 76):157-65

28. Domiciano DS, Bonfá E, Borges CTL, et al. A long-term prospective randomized controlled study of non-specific interstitial pneumonia (NSIP) treatment in scleroderma. Clin Rheumatol. 2011;30:223-9.

29. Trang G, Steele R, Baron M, Hudson M. Corticosteroids and the risk of scleroderma renal crisis: A systematic review. Rheumatol Int. 2012;32:645-53.

30. Steen VD, Medsger TA. Case-control study of corticosteroids and other drugs that either precipitate or protect from the development of scleroderma renal crisis. Arthritis Rheum. 1998;41:1613-9.

31. Ando K, Motojima S, Doi T, et al. Effect of glucocorticoid monotherapy on pulmonary function and survival in Japanese patients with scleroderma-related interstitial lung disease. Respir Investig. 2013;51:69-75.

32. Adler S, Huscher D, Siegert E, et al. Systemic sclerosis associated interstitial lung disease - individualized immunosuppressive therapy and course of lung function: Results of the EUSTAR group. Arthritis Res Ther. 2018;20:17.

33. Hoyles RK, Ellis RW, Wellsbury J, et al. A multicenter, prospective, randomized, double-blind, placebo-controlled trial of corticosteroids and intravenous cyclophosphamide followed by oral azathioprine for the treatment of pulmonary fibrosis in scleroderma. Arthritis Rheum. 2006;54:3962-70.

34. Richeldi L, du Bois RM, Raghu G, et al. Efficacy and safety of nintedanib in idiopathic pulmonary fibrosis. N Engl I Med. 
Review Interstitial Lung Disease

2014;370:2071-82.

35. Wollin L, Wex E, Pautsch A, et al. Mode of action of nintedanib in the treatment of idiopathic pulmonary fibrosis. Eur Respir J. 2015;45:1434-45.

36. Atanelishvili I, Akter T, Noguchi A, et al. Antifibrotic efficacy of nintedanib in a cellular model of systemic sclerosis-associated interstitial lung disease. Clin Exp Rheumatol. 2019:37:115-24.

37. Huang J, Beyer C, Palumbo-Zerr K, et al. Nintedanib inhibits fibroblast activation and ameliorates fibrosis in preclinical models of systemic sclerosis. Ann Rheum Dis. 2016;75:883-90.

38. Huang J, Maier $C$, Zhang Y, et al. Nintedanib inhibits macrophage activation and ameliorates vascular and fibrotic manifestations in the Fra2 mouse model of systemic sclerosis. Ann Rheum Dis. 2017;76:1941-8.

39. US Food and Drug Administration. FDA approves first treatment for patients with rare type of lung disease. 2019. Available at: www.fda.gov/news-events/press-announcements/fda-approvesfirst-treatment-patients-rare-type-lung-disease (accessed December 16, 2019)

40. Flaherty KR, Wells AU, Cottin V, et al. Nintedanib in progressive fibrosing interstitial lung diseases. N Eng/ J Med. 2019;381:1718-27.
41. Goh NSL, Desai SR, Veeraraghavan S, et al. Interstitial lung disease in systemic sclerosis: A simple staging system. Am I Respir Crit Care Med. 2008;177:1248-54.

42. Morisset J, Vittinghoff $\mathrm{E}$, Elicker BM, et al. Mortality risk prediction in scleroderma-related interstitial lung disease. Chest. 2017;152:999-1007.

43. Fischer A, Strek ME, Cottin V, et al. Proceedings of the American College of Rheumatology/Association of Physicians of Great Britain and Ireland Connective Tissue Disease-Associated Interstitial Lung Disease Summit: A Multidisciplinary Approach to Address Challenges and Opportunities. QJM. 2019;112:81-93. 